\title{
Symptoms of post-traumatic stress disorder in victims of trafficking Christina Antonopoulou ${ }^{* 1}$ and Nicoletta Skoufalos ${ }^{2}$
}

\author{
Address: ${ }^{1}$ University of Athens, Greece and ${ }^{2}$ Fordham University, USA \\ * Corresponding author
}

\author{
from International Society on Brain and Behaviour: 2nd International Congress on Brain and Behaviour \\ Thessaloniki, Greece. 17-20 November 2005 \\ Published: 28 February 2006 \\ Annals of General Psychiatry 2006, 5(SuppI I):SI 20 doi:I0.II86/I744-859X-5-SI-SI 20
}

\section{Background}

Recently studies have emerged that examine various traumatized populations, which have shed light on the course of Post Traumatic Stress Disorder (PTSD). The differences in the symptomatology of PTSD between "at risk" populations must be understood, so that people are not misdiagnosed and therapeutic interventions are tailored to each group. The purpose of this study was to examine the symptoms of PTSD in victims of trafficking, an under researched population, and to establish how their symptoms differ from those experienced by other victims of abuse and by females in the general population of Greece.

\section{Materials and methods}

Fifty-two females, ages 17 to 65 completed the Trauma Syndrome Inventory (TSI), 26 from the general population and 26 from a women's shelter. Of the 26 women in the shelter, 11 are victims of trafficking. The 26 participants from the women's shelter also completed the Brief Betrayal Trauma Survey (BBTS). A one way Analysis of Variance was computed to determine whether there were significant differences in symptomatology between the females from the general population, the women in the shelter, and the victims of trafficking.

\section{Results}

Significant differences were found between the females from the general population, the abused women, and the victims of trafficking on the TSI and BBTS. The abused women's mean scores on the TSI were significantly higher than the scores of the non-abused women. However the victims of trafficking demonstrated a unique presentation of trauma symptoms. The victims of trafficking also responded significantly different on the BBTS than the other abused women.

\section{Discussion}

According to the National Center for PTSD (2000), people who are most likely to develop PTSD are those who experience greater stressor intensity, uncontrollability, and sexual victimization. These experiences personify the reality of trafficking. Our results suggest that victims of trafficking are a group of abused women who are at higher risk for developing PTSD. Not only have these women's symptoms met the DSM-IV-TR criteria for PTSD, but they also display additional pathology. It is necessary to be aware of the varieties of PTSD symptoms and to practice a treatment modality that is sensitive to this group's specific situation.

\section{References}

I. American Psychiatric Association: Diagnostic and Statistical Manual of Mental Disorders 4th edition. Washington DC; 2000.

2. Shalev AV, Peri T, Canetti L, Schreiber S: Predictors of posttraumatic stress disorder in injured trauma survivors: $A$ prospective study. American Journal of Psychiatry 1996, 153:219-225.

3. Fairbank JA, Brown TA: Current behavioral approaches to the treatment of posttraumatic stress disorder. The Behavior Therapist 1987, 3:57-64.

4. van der Kolk BA, Dreyfus D, Michaels M, Shera D, Berkowitz R, et al.: Fluoxetine in posttraumatic stress disorder. Journal of Clinical Psychiatry 1994, 15:517-523. 